\title{
USING FAST-TIME SIMULATIONS FOR DESIGNING AND OPERATING AIRPORT TERMINALS AS NODES OF INTERMODAL TRANSPORT
}

Ever growing traffic in air transport with associated capacity constraints brings problems to air passenger flows at airports. There is strong link between quality of airport ground access system and airport terminal operations. However, this aspect remains underestimated in the development plans of many airports all over the world, which results in underutilization of both planed and existing infrastructure. In efforts for improvement, the higher level of synchronization and coordination between air and ground transport needs to be achieved. For this purpose, a computer model enabling to simulate passenger flows within airport's catchment area has been developed by the Air Transport Department, University of Zilina. Thanks to this simulation model, it is possible to perform comprehensive operational, economic and environmental assessment of the innovative airport ground access concepts and thus facilitate designing and operating airports as nodes of intermodal transport.

Key words: Passenger flow model; design and operations of airport terminals; fast-time simulations; airport ground access; operational, economic and environmental assessment.

\section{Introduction}

Due to physical and nuisance constraints the airports have always been built far from the city centres and their operations have always been dependent on the ground transport [2]. As the passenger trip does not start or finish at the airport, the speed that is considered to be the primary advantage of the air transport is being reduced by ground portion of the trip. This fact influences the competitiveness of both airport and air transport especially on short-haul trips. When selecting the transport mode, the total time of transportation 'from door to door' is one of the most important decisive factors for passenger. The attractiveness of the airport and air transport at the same time significantly decreases if the time of access by surface transport exceeds a certain maximum time. For short haul trips this should not exceed 30 minutes, while two hours or more might be acceptable for long haul flights [1].

However, the airport competitiveness is not the only factor that is influenced by airport access/egress link:

- Size of the catchment area: The quality of ground transport can significantly influence the size of the catchment area and give an airport a competitive advantage over other airports in the region [1].

- Airport's finances: High share of individual car access trips requires investments into constructing multi-level car parks in the terminal buildings vicinity. On the other hand, revenues from parking fees represent an important part of airport revenues [1].

- Terminal operations and capacity: Access trip duration and access mode reliability significantly influences the arrival earliness pat- tern of passengers. This consequently has an impact on time spent by passengers in the terminal building prior to their departure and on utilisation of terminal facilities [3].

- Environment: Traffic generated by the airport has a major influence on the surrounding environment. This influence increases with the size and throughput of the airport, its proximity to the built up residential area and with the share of individual car access trips [4].

Despite these facts, the problems of airport ground access are still being underestimated. Many studies dealing with the problems of airport landside operations are focused mainly on the processing part of the airport terminal and consider the airport terminal to be an isolated system. Even most of airport landside operations models developed using either generic or dedicated simulation software packages (e.g. PaxSim, SLAM, WITNESS, ARENA or EXTEND) are designed for simulating the passenger and baggage flows only between curb-side and apron. Although this approach provides valuable data concerning capacity, delays or processing bottlenecks, in some cases, identified capacity constraints are only the symptoms of the actual problem. In order to identify the cause of the problem, it is necessary to consider the airport terminal as an integral part of much more complex regional, national or international transportation system.

In order to fill this gap in research and development, our research aims at developing passenger flow model that would be able to simulate passenger flows from the place of origin (e.g. home or office) to the airport and back. Thanks to this model, it is pos-

\footnotetext{
* Benedikt Badanik, Milan Stefanik, Martin Matas

Air Transport Department of the University of Zilina, Slovakia, E-mail:bedendikt.badanik@fpedas.uniza.sk
} 
sible to consider airport as an integral part of the whole transport chain rather than isolated system (i.e. from curb to curb) and thus analyse and investigate the relationship between traffic flows within airport's catchment area and terminal operations. The result of our research and development is Airport Ground Access and Egress Passenger Flow model (AGAP model) that simulates passenger flows from door to curb. On top of that, the AGAP model in combination with some of airport landside operations models enables to simulate passenger flows within entire door-to-door transportation process. Thanks to this feature, the AGAP model represents a powerful tool allowing user to perform comprehensive operational, economic and environmental assessment of innovative airport ground access concepts.

\section{Airport Ground Access and Egress Passenger Flow model}

AGAP model has been developed using MS Excel and Visual Basic programming environment. As it has already been mentioned, the model enables to simulate passenger flows from the place of passenger's origin to the airport and back. Thanks to this airport ground access/egress passenger flow model, it is possible to simulate passenger flows within the airport's catchment area to and from the airport and to investigate the interactions between airport ground access/egress and airport terminal operations [8], [13], [14] and [15].

The Airport Ground Access and Egress Passenger Flow model is a stochastic microscopic computer-based model that simulates entire airport access/egress related traffic within airport's catchment area. Its scope begins at the place of passenger's origin/destination and ends in the airport terminal. The model consists of the following two modules (see Fig. 1):

(1) Air passenger trips generation module (see light grey area in Fig. 1): This module is responsible for simulating the demand distribution within the airport's catchment area. Based on the input data this module allocates passengers to particular flights, generates passenger groups and passenger distribution to the cities within airport's catchment area.

(2) Passenger transport mode choice module (see dark grey area in Fig. 1): This module is responsible for simulating passenger airport ground access/egress mode choice. Based on outputs from air passenger trips generation module this module selects the most favourable airport access/egress transport mode taking into account price, travel time and convenience. This module employs algorithm of passenger behaviour.

\subsection{Air Passenger Trips Generation Module}

A flight schedule is the source of primary input data for generation the air passenger trips. Before the flight schedule can be imported into the AGAP model, it has to be supplemented by additional information and all the data needs to be pre-processed to ensure they are in correct format. A completed flight schedule contains the following information on each flight:
- Flight number

- Scheduled and actual time of departure

- Destination airports

- Aircraft operator, aircraft type and seat capacity, load factor

- Indication if flight is international or domestic; scheduled or charter

- Indication if flight's destination is a holiday resort

- Share of business and leisure passengers in flight

- Possible times of arrival (assuming that passenger uses services of the same operator for both outbound and inbound flights)

Based on the information from the flight schedule (i.e. based on flight type, destination, aircraft capacity, load factor, and proportion of leisure and business passengers) the model allocates passengers to each particular flight. The characteristics related to passenger flows within airport's catchment area are then randomly generated and assigned to each passenger based on relevant probability distributions.

In the first step of the algorithm, the model generates the sizes of passenger groups. The air passengers often travel in groups of various sizes (e.g. families, couples, friends, business partners etc.). The group sizes are different for business and leisure passengers (see Fig. 2). Each passenger type has a probability distribution of the group size. These probability distributions are used to generate passenger groups for the flight. The algorithm generates the groups in the cycle until the number of passengers reaches the actual number of passengers in the each particular flight from the flight schedule.

In the second step, the model assigns the place of trip origin/ destination to each group of passengers. The region of the trip origin/destination is randomly assigned to each passenger group based on probability distribution that reflects the distribution of air transport demand within the airport's catchment area. The city of the trip origin/destination is randomly assigned to each passenger group based on the population distribution within particular region. The assignment of region and city of passenger's origin/ destination is proportional. It means that if a particular region has higher air transport demand than another one, the probability that the passengers are from this region is proportionally higher. Same analogy is used in the case of city assignment. It means that if a city within particular region has higher population than another one within the same region, the probability that the passengers are from this city is proportionally higher.

In the third step, model randomly generates length of passengers' stays in their flight destination. The following figures depict passengers' stay length distribution (see Fig. 3 and Fig. 4). This parameter is important for assigning proper inbound flight to each passenger. On top of that, this parameter directly influences parking fees at the airport, which has direct impact on transport mode choice.

All the above mentioned characteristics were identified to be the key factors influencing the airport ground access mode choice process. By assigning these characteristics to each passenger, the 


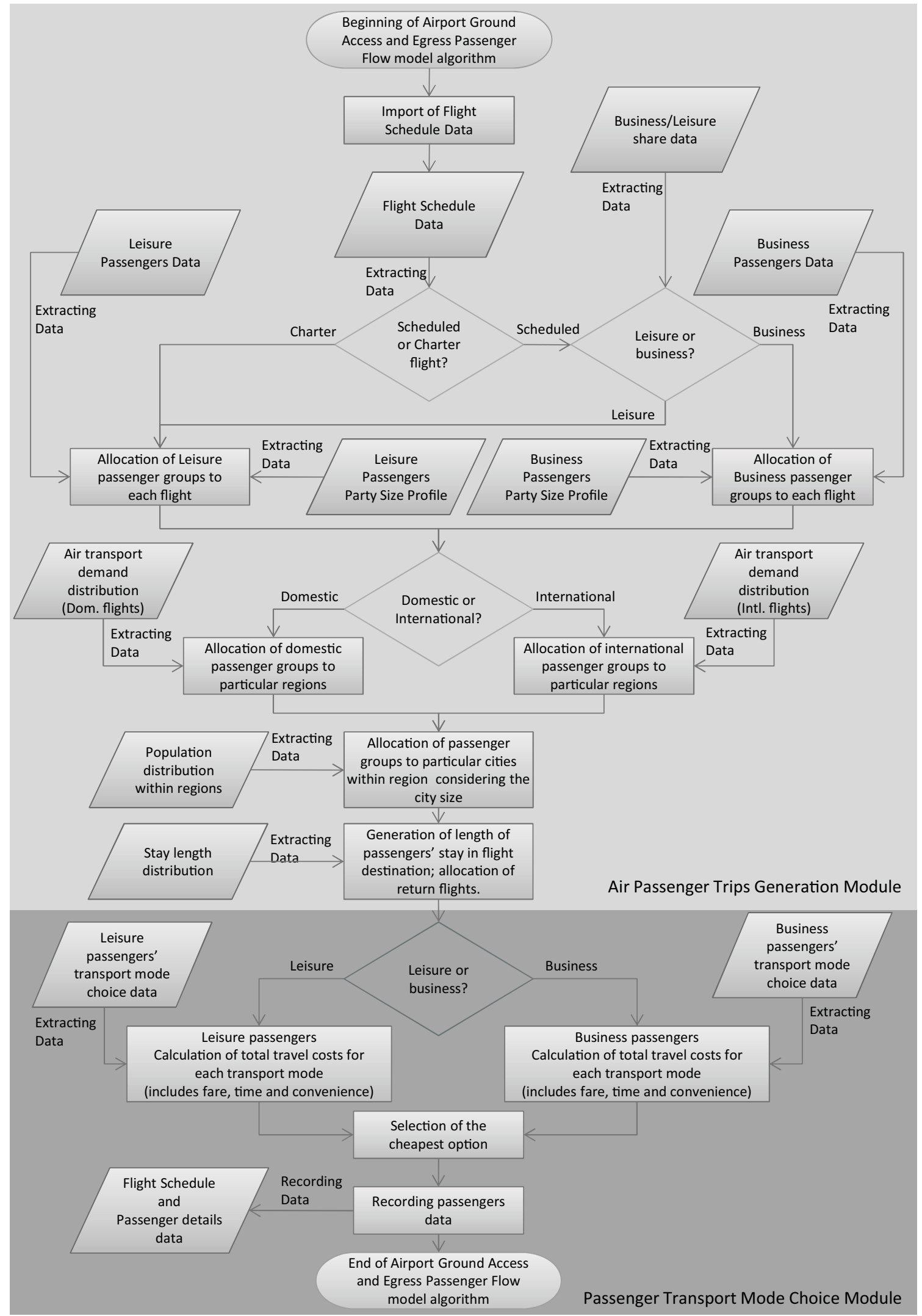

Fig. 1 Airport Ground Access and Egress Passenger Flow model Algorithm 


\section{Leisure passengers: Size and proportion of groups}

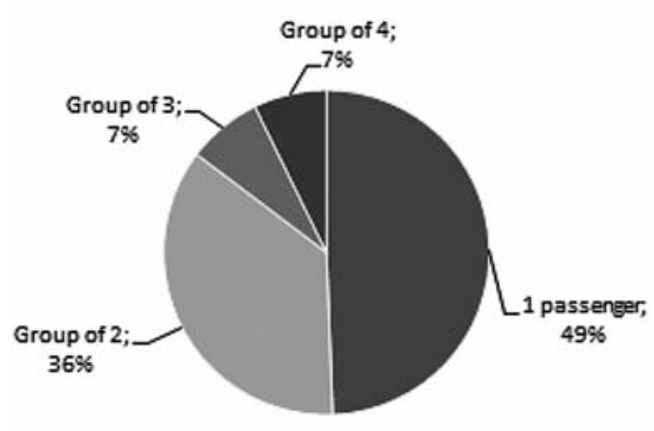

\section{Business passengers: Size and} proportion of groups

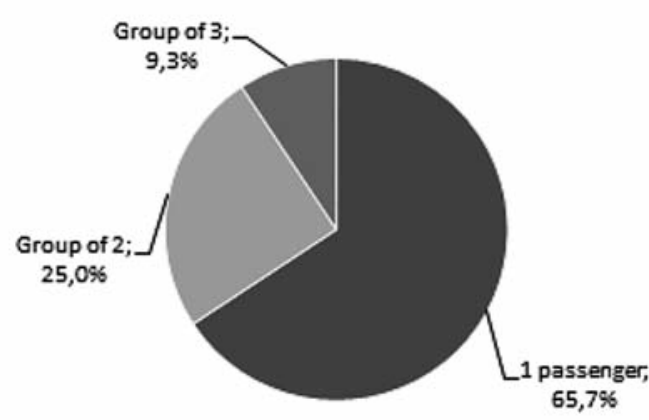

Fig. 2 Size and proportion of passenger groups (Source: Bratislava airport)

\section{Leisure passengers: Stay length distribution}

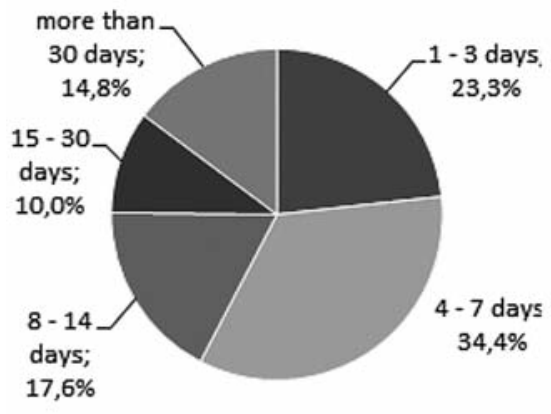

Business passengers: Stay length distribution

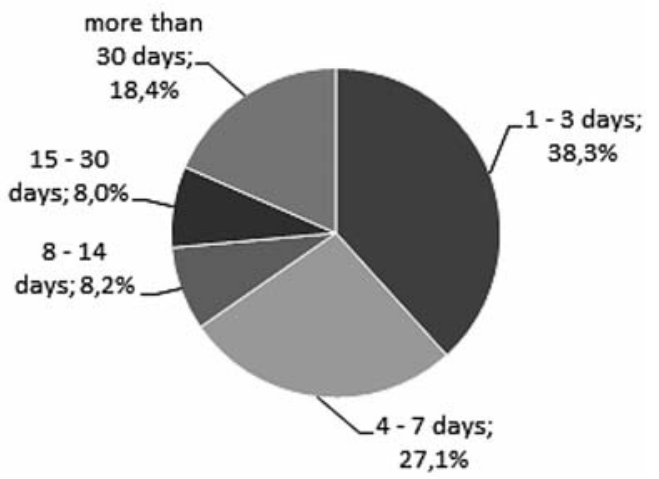

Fig. 3 Scheduled flights: Passengers' stay length distributions (Source: Bratislava airport)

\section{Charter flight passengers: Stay length distribution}

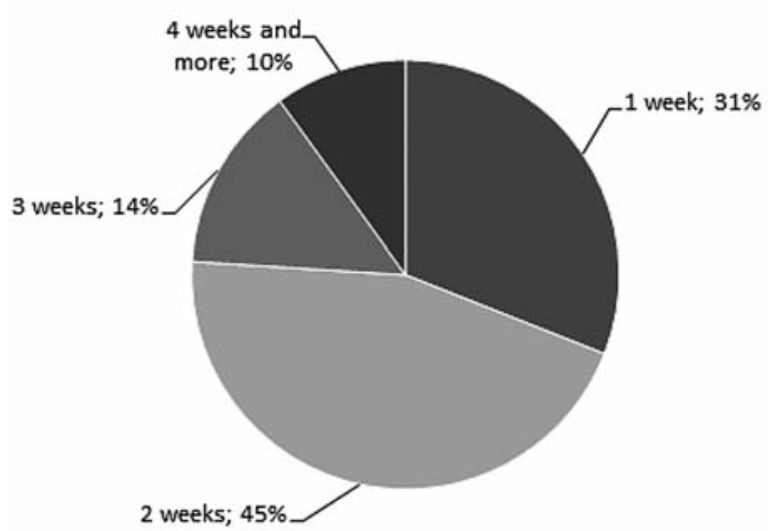

Fig. 4 Charter flights: Passengers' stay length distributions (Source: Bratislava airport)

Air Passenger Trips Generation Module defines a very complex passenger typology.

\subsection{Passenger Transport Mode Choice Module}

The algorithm of passenger transport mode choice that is used in the AGAP model is based on evaluation of the perceived costs of each transport mode. Thanks to this approach, it is possible to consider both quantitative and qualitative factors influencing the passenger mode choice. The AGAP model automatically selects the most favourable option in terms of price, travel time and convenience for each passenger.

The perceived costs of transport consist of the financial costs, time costs and transfer costs. The financial costs represent the money value needed to get from the place of origin to the airport and back including all related charges such as parking fees in case of car transport etc. The time costs represent a perceived value of in-vehicle travel time and excess travel time (i.e. waiting, walking, transfer time, etc.). The transfer costs represent a perceived value of additional physical and cognitive effort resulting from the transfer, and perceived value of risk of missing the connection. Both value of time and value of transfer were quantified based on average passenger income. Thanks to this approach, it was possible to con- 
sider price sensitivity and time sensitivity of particular types of passengers (see Tab. 1).

Recommended Travel Time Values [16], [17]

Tab. 1

\begin{tabular}{|l|c|}
\hline Time component & Relative to wages \\
\hline In-vehicle Personal (local) & $50 \%$ \\
\hline In-vehicle Personal (intercity) & $70 \%$ \\
\hline In-vehicle Business & $120 \%$ \\
\hline Excess (waiting, walking, or transfer time) Personal & $100 \%$ \\
\hline Excess (waiting, walking, or transfer time) Business & $120 \%$ \\
\hline
\end{tabular}

The AGAP model evaluates perceived costs of the following airport access/egress transport modes:

- Individual car - 'Kiss and drive'

- Individual car - 'Park and fly'

- Taxi

- Public city transport

- National public transport + Taxi

- National public transport + Public city transport

Before AGAP model starts to calculate the perceived costs for particular airport access/egress modes, it has to calculate distances, travel times, waiting times and number of transfers for each airport access/egress option.

In the case of access/egress trips by individual cars (i.e. 'Kiss and drive' and 'Park and fly'), model gathers all the required information regarding distances and travel times from the database containing comprehensive information on road network within airport's catchment area. The time when passenger arrives at the airport before STD (Scheduled Time of Departure) of his/her aircraft is randomly generated by the model using normal probability distribution. The time when passenger leaves the airport after ATA (Actual Time of Arrival) of his/her aircraft is defined by fixed value that is estimated based on analysis of the arrival processes at particular airport.

The information related to access/egress trips by taxi are calculated and processed using same approach as in the case of individual car trips. The only difference is that in the case of taxi trip, the model randomly generates time that passenger spends by waiting for a taxi.

The information regarding national/urban public transport between particular parts of catchment area and airport are gathered from the actual public transport timetable database. The public transport timetable database contains information regarding travel times, service frequency, departure/arrival times and number of transfers for all public transport connections within the airport catchment area. The model selects the most favourable outbound and inbound connections from the database, considering the following factors:

- Passenger's itinerary defined by departure/arrival time of his/ her flight;
- Price of the connection;

- Total travel and waiting times;

- Number of transfers.

The time when passenger arrives at the airport before STD of his/her aircraft is given by the public transport itinerary of particular passenger. The time when passenger leaves the airport after ATA of his/her aircraft is given by the arriving processes at the particular airport and by time that passenger spends by waiting for the public transport connection (calculated based on the public transport itinerary).

When the model compiles a set of traffic flow related information (i.e. distances, travel times, waiting times, transfers, dwell times in terminal etc.) for each airport ground access/egress option considering a specific needs and requirements of each particular passenger, it is ready to calculate perceived costs. The value of perceived costs for all of above listed airport access/egress transport modes is calculated using the following equation (1). The perceived costs are calculated for return trip as we assumed that passengers will use same transport mode for travelling to the airport as well as from the airport. We also assumed that when choosing airport ground access/egress mode, the passenger considers perceived costs of both outbound and inbound trip.

$$
\begin{aligned}
& \text { Perceived Costs }=\text { Financial Costs }+ \text { Time Costs }+ \\
& + \text { Transfer Costs [Eur] }
\end{aligned}
$$

Formulae for calculating particular elements of the equation depicted hereinbefore (i.e. for calculating financial costs, time costs and transfer costs) are significantly more complex. Moreover, each of considered airport ground access option has separate formula for calculating financial costs, time costs and transfer costs. For this reason, it was not possible to list all used formulae in this paper. On the other hand, the approach used for calculating these parameters was clearly described in the text hereinbefore. Detailed description of the Passenger Transport Mode Choice Module algorithm including all used formulae can be found in [15].

Assuming that airport access/egress ground transport mode with the lowest perceived costs would be the passenger's choice the AGAP model assigns the cheapest transport option to particular passenger. From statistical point of view, the selection of the cheapest option in terms of perceived costs is justifiable approach. However, we are aware that this approach does not fully reflect the actual process of transport mode selection as it automatically excludes more expensive options. In real life, the cheapest option represents the highest probability of choice and the most expensive option represents the lowest probability of choice. It means that any of considered options has probability of choice greater than zero. This issue is going to be solved within further research by incorporating a more sophisticated demand modelling algorithm into the AGAP model.

The main data output from the Airport Ground Access and Egress Passenger Flow model is an Excel spreadsheet where the 
information about the passengers is stored. It includes the passenger ID number, place of origin, group size, transport time etc. The most important aggregate information includes:

- Total travel time

- Total distance travelled

- Travel costs

- Arrival earliness distribution of passengers

The travel time, distance travelled and travel costs are used as performance indicators necessary for the analysis of passenger flows within the airport catchment area and for comprehensive operational, economic and environmental assessment of the airport ground access/egress solutions. The arrival earliness pattern is key information for assessing the impact of airport ground access/ egress on the airport terminal operations.

When performing operational, economic and environmental assessment of some airport ground access concept, the AGAP model simulates the airport access/egress part of the door-to-door transportation chain (i.e. between passenger origin/destination and entrance of the airport terminal). In order to investigate the impact of airport access/egress on passenger processing within the airport terminal, it is necessary to use some of airport landside operations models. In such a case, the outputs from AGAP model are used as inputs for airport landside operations model.

At this stage of research and development, the AGAP model is customised for simulating passenger flows within catchment area of Bratislava airport. Operation division and Marketing \& Commerce division of the Bratislava airport supported this research initiative and provided us with all the data necessary for calibration and validation of the model.

\section{AGAP model verification and validation}

The model assumptions are based on extensive passenger survey at Bratislava airport (performed during summer season in 2003, 2004 and 2007) and also on operational data collection exercise that was performed at Bratislava airport and at Brno-Turany airport.

During the design process of the model we created a sample of 100 passengers (randomly generated). For these 100 passengers, we calculated all the parameters manually (e.g. group size, place of origin/destination within airport's catchment area etc.). During entire development process the functionality and accuracy of the AGAP model was verified using this testing sample of 100 passengers. Thanks to this verification process, we reduced the probability of creating the software bugs.

In order to validate used algorithms and verify assumptions that were taken into account the simulation results were compared with actual operational data. The AGAP model validation showed that the simulation results approximate the real operations. The simulation results accuracy was verified by means of the following parameters:

- Arrival earliness distribution of passengers (see Fig. 5);
- Proportion of airport ground access/egress transport modes (see Fig. 6).

As can be seen from the charts the simulation results correspond to the actual operational data.

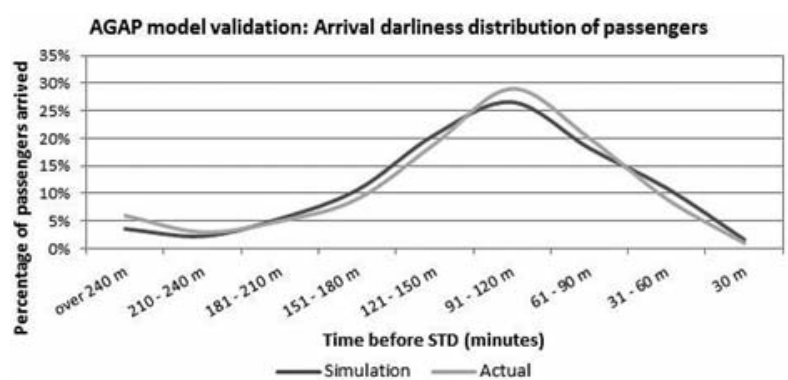

Fig. 5 AGAP model validation: Arrival earliness distribution of passengers

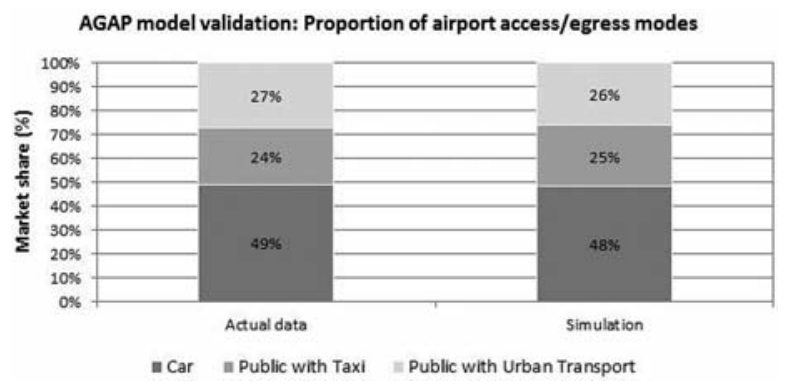

Fig. 6 AGAP model validation: Proportion of airport access/egress transport modes

\section{Making AGAP model an efficient tool for airport design and planning}

The operational capabilities of the AGAP model have already been used for operational, economic and environmental assessment of two innovative airport design concepts hypothetically implemented in the Bratislava airport environment:

'Pick-up/Drop-off' airport ground access concept: Using the AGAP model for simulation of passenger flows within the airport's catchment area and PaxSim model for simulation of passenger and baggage flows inside airport terminal, we compared current design of airport ground access/egress system at Bratislava airport with an innovative concept based on dedicated minibus network serving the entire catchment area. The minibus network was designed for collection, transportation and distribution of air passengers. Operation of minibuses within this network would be based on the analogy of collection, transportation and distribution of consignments within express carriers' regional distribution network. This principle would allow introducing a high-level coordination and synchronization between air and ground transport. The simulations 
showed that the proposed 'Pick-up/Drop-off' airport ground access concept would significantly contribute to improvement of passenger flow efficiency and passenger processing efficiency, which would consequently be reflected in reduction of travel times, reduction of dwell times and reduction of travel costs. On the other hand, expected positive impact of more efficient passenger flows on the environment (based on simulation results) turned to be negligible [8], [13] and [15].

Airside-Landside separation concept: This concept is based on the physical separation of the landside from airside and connecting these two with the synchronised and coordinated high-speed transport means. Their idea is based on bringing the terminal areas back to the city while the runways could be built far from the city, where the capacity extension constraints are significantly lower than those in the city area. While this concept would potentially bring operational assets to future airports, our simulation proved that in terms of passenger flow efficiency the concept would not bring any significant benefits. The concept could even cause longer dwell times compared to conventional airport concepts [11], [12] and [14].

\section{Conclusions and recommendations for future work}

This paper describes and demonstrates the capabilities of the AGAP model that can be used for performing operational, economic and environmental assessment of future airport design concepts. This simulation model enables to perform fast-time simulation of door-to-door passenger flows and thus allows seeing the airport terminal as an integral part of regional, national or international transportation network. Thanks to this fact, it is possible to analyse the interactions between airport ground access/egress and passenger and baggage flows inside airport terminal building. The new method based on using the AGAP model reveals an innovative approach to performing comprehensive operational and environ- mental assessments of future airport design concepts.Using this new method, we have already performed an operational, economic and environmental assessment of two innovative airport design concepts. Thanks to microscopic simulation of door-to-door passenger flows we were able to conduct initial feasibility assessment of these concepts and identify their potential benefits and drawbacks.

More comprehensive validation of model outputs will enable using a developed simulation model as a decision making support tool in real operations.

Within further research, we will also focus on the following issues:

- Development of more sophisticated algorithms of passenger transport mode choice (e.g. current model assigns each passenger with the cheapest transport option, which does not fully reflect the actual passenger preferences);

- Integration of algorithms reflecting the probability of delay in both, air and ground transport.

Although algorithms incorporated in the AGAP model are generic and could be used for evaluation of airport ground access system at any airport, the model itself is customized for the Bratislava airport operational conditions. The simulation of passenger flows within airport's catchment area is very demanding in terms of availability of operational and statistical data. Moreover, data collected at one airport cannot be used for evaluating the airport ground access system at another airport as operational conditions at each airport are unique. Due to operational data availability, Bratislava airport was the number one choice when developing the AGAP model. Management of Bratislava airport was willing to cooperate with us in this research initiative and provided us with comprehensive set of required operational and statistical data. For this reason, in all studies that were conducted using the AGAP model, Bratislava airport was used as a case study.

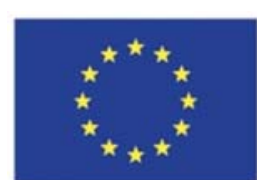

Európska únia

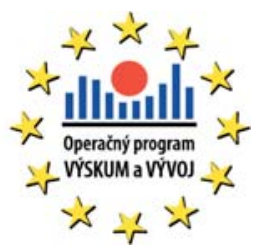

We support research activities in Slovakia/Project is co-financed by EU Centre of Excellence for Air Transport ITMS 26220120065

\section{References}

[1] KAZDA, A., CAVES, R. E.: Airport Design and Operations, Second Edition; Elsevier, 2007

[2] M3 Systems, ANA, ENAC, LEEA: CARE II: The Airport of the Future: Central Link of Intermodal Transport? WP1: Review of current intermodality situation; EUROCONTROL Experimental Centre; October 2004

[3] ASHFORD, N., STANTON, H. P. M., MOORE, C. A.: Airport Operations, Second Edition; McGraw-Hill; 1997

[4] IATA: Airport Development Reference Manual, 9th Edition, IATA, 2004

[5] TETHER, B., METCALFE, S.: Horndal at Heathrow? Cooperation, Learning and Innovation: Investigating the Processes of Runway Capacity Creation at Europe's Most Congested Airports, The University of Manchester, UMIST, June 2001. 
[6] NEUFVILLE, R., ODONI, A. R.: Airport Systems: Planning, Design and Management, McGraw-Hill, 2003.

[7] Preston Aviation Solutions, PaxSim Solutions User Manual, Preston Aviation Solutions Pty Ltd., 2006.

[8] STEFANIK, M.: Problems of Airport Capacity Assessment, Doctoral Thesis, University of Zilina, 2009.

[9] ASHFORD, N., STANTON, H. P. M., MOORE, C. A.: Airport Operations, $2^{\text {nd }}$ Edition, McGraw-Hill, 1997.

[10] COKASOVA, A.: Analysis of Passenger Viewpoints and of the Practical Shift in Air Rail Intermodal Transport, PhD. dissertation, University of Zilina, 2006.

[11] MATAS, M.: Future Airport Concept, University of Zilina and Eurocontrol Experimental Centre; 2004

[12] MATAS, M., BROCHARD, M.: The Airport of the Future or what can be the Airport in the Year 2020 and After?, Eurocontrol Experimental Centre Innovative Research Activity Report; 2004.

[13] STEFANIK, M., BADANIK, B., MATAS, M.: Designing Sustainable Airport Ground Access/Egress Systems Supported by Fasttime Modelling; J. of Civil Engineering and Architecture; Vol. 4; No. 9; September 2010

[14] MATAS, M., STEFANIK, M., KROLLOVA, S.: Door-to-Gate Air Passenger Flow Model; $4^{\text {th }}$ Int'1 Conference on Research in Air Transportation, ICRAT 2010; Budapest; June 2010

[15] STEFANIK, M.: Airport Landside Capacity: Making Airports Intermodal Transport Nodes; Lambert Academic Publishing; January 2011.

[16] TCRP: Report 78 - Estimating the Benefits and Costs of Public Transit Projects: A Guidebook for Practitioners; Transit Cooperative Research Program; Transportation Research Board of the National Academies; 2002

[17] LITMAN, T.: Valuing Transit Service Quality Improvements Considering Comfort and Convenience in Transport Project Evaluation; Victoria Transport Policy Institute; 2008. 